\title{
Acoustic ontogeny of a teleost
}

\author{
J. K. Horne \\ University of Washington, School of Aquatic and Fishery Sciences, Box 355020, \\ Seattle, WA 98195-5020, U.S.A.
}

(Received 15 March 2007, Accepted 10 July 2008)

\begin{abstract}
The influence of growth on the intensity and variability of acoustic echoes from individuals and groups of a teleosts was quantified using Donaldson trout (rainbow-steelhead hybrid) Oncorhynchus mykiss. Fish growth was linear in total length $\left(L_{\mathrm{T}}\right)$ and quadratic in mass. Dorsal swimbladder area increased exponentially with $L_{\mathrm{T}}$. Allometric growth ratio (i.e. $k$ ) values of swimbladder length linearly increased with $L_{\mathrm{T}}$. Average swimbladder volumes occupied 3-6\% of fish body volume and increased exponentially with $L_{\mathrm{T}}$. The aspect angle that resulted in the maximum average acoustic intensity from the group shifted from 80 to $86^{\circ}$ through the experimental period. Mean echo intensities increased at both 38 and $120 \mathrm{kHz}$ as mean $L_{\mathrm{T}}$ increased. Predicted echo intensities at $38 \mathrm{kHz}$ exceeded that at $120 \mathrm{kHz}$ at $L_{\mathrm{T}}<150 \mathrm{~mm}$ but were less than that predicted at $120 \mathrm{kHz}$ at $L_{\mathrm{T}}>280 \mathrm{~mm}$. Generalized additive mixed models using $L_{\mathrm{T}}$, swimbladder angles and lateral elongation ratios of fish bodies were better predictors of echo intensities than $L_{\mathrm{T}}$ alone.

(C) 2008 The Author

Journal compilation (C) 2008 The Fisheries Society of the British Isles
\end{abstract}

Key words: backscatter model; Donaldson trout; swimbladder; target strength.

\section{INTRODUCTION}

The growth history and development of individuals, known as ontogeny, are non-linear and indeterminate over the life span of a fish (Barton, 1996). If ontogeny of the swimbladder and body are non-linear (i.e. allometric), then agedependent changes in shapes and sizes of body components are important when estimating fish lengths and densities from acoustic data. McClatchie et al. (1996, 2003) identified the need to examine how allometric growth in swimbladder length, cross-section and overall fish length affect echo intensities (i.e. target strengths) of swimbladdered fishes. Swimbladders are especially important since they reflect a minimum of $90 \%$ of the acoustic energy from individual fishes (Haslett, 1962; Foote, 1980a) and vary in shape and size within (Foote, 1985) and among (Whitehead \& Blaxter, 1964) fish species. Conversion of reflected energy (i.e. backscatter) to fish length is based on species-specific, empirical relationships between backscatter from isolated targets and known fish lengths. Backscatter and fish length data can be measured directly in controlled

Tel.: +12062216890; fax: +12062216939; email: jhorne@u.washington.edu 
conditions (McCartney \& Stubbs, 1971; Nakken \& Olsen, 1977) or indirectly by combining field backscatter measurements from individual fish (i.e. in situ) with coincident length samples from directed net hauls (Foote \& Traynor, 1988; Cordue et al., 2001).

Accuracy and precision of backscatter to fish length conversions are dependent, in part, on the samples used in the regression equation. Target strength (TS) to fish length relationships may be based on samples that encompass a limited length range (Williamson \& Traynor, 1984), include a mixture of several cohorts and are assumed to be normally distributed. Caution must be used when converting TS values to fish lengths from samples that were not used in the formulation of the original regression equation (Horne, 2003). A single regression relationship between TS and fish length may not be appropriate for a population containing both small and large fish. Precision of TS to fish length relationships derived using indirect methods (i.e. in situ measurements) may be further reduced when multimodal TS distributions are matched to unimodal length frequency distributions (Williamson \& Traynor, 1984). In this case, it is not known if the net was selectively catching large fish or if single targets were reflecting multiple echoes.

Potential ontogenetic differences among life-history stages and among individuals suggest the need to quantify changes in swimbladder and body shapes. From an acoustic perspective, changes in swimbladder size and shape may increase variability in backscatter from groups of animals, may change TS to fish length relationships over specified length ranges and may ultimately decrease accuracy of acoustic-based abundance estimates. This study examines effects of growth on the acoustic characteristics of individuals within a group of teleosts.

\section{MATERIALS AND METHODS}

Thirty-five Donaldson trout Oncorhynchus mykiss (Walbaum), a rainbow-steelhead hybrid known for their rapid growth, were obtained from and maintained at the University of Washington, School of Aquatic and Fishery Sciences Fish Hatchery in Seattle, Washington, U.S.A., from October 2001 to May 2002. Fish were kept in small raceways until overcrowding necessitated a change to larger holding tanks. To stimulate growth during winter, heated water was added to holding tanks from January to the end of February 2002. Lake Washington water was used from March until the end of the experiment. Fish were regularly fed to repletion using Moore-Clark Nutra Fry (1.2 mm to 4.0 $\mathrm{mm}$; Vancouver, British Columbia, Canada) and when larger, Pedigree Salmon Brood (5.0-12 mm; Moore-Clark) fish pellets except for 2 days prior to each radiography session. The cessation of feeding minimized undigested food in the stomach to provide an index of maximum potential backscatter. Feeding was resumed immediately after each measurement session. To ensure identification of individuals during the study, each fish was injected with a passive integrated-transponder (PIT) tag (Unimark, $2 \times 12 \mathrm{~mm}$; Boise, ID, U.S.A.). Fish were observed to recovery quickly from tagging. Lower et al. (2005) showed that cortisol levels in fishes implanted with PIT tags returned to pre-stress levels within $12 \mathrm{~h}$.

Sixteen rounds of dorsal and lateral radiographs were taken during the 8 month growout period. Fish were individually netted and then transferred in small batches from the raceway or holding tank to an anaesthetic bath containing 50-60 ppm clove oil (eugenol) solution. The number of fish anaesthetized in each batch was dependent on the number of fish that could be imaged on a single piece of radiographic film. The fish 
were left in the anaesthetic bath until they had reached stage four anaesthesia (i.e. total loss of muscle tone and equilibrium, slow but regular opercular pumping and loss of spinal reflexes; Summerfelt \& Smith, 1990). Fish were transferred to radiograph film holders or rare-earth cassettes and radiographs were taken in both lateral and dorsal planes (XTEC 90P Laseray plus; Columbia City, IN, U.S.A.). Exposure settings varied among sessions, with intensity $(\mathrm{kVp})$ and time increasing as the fish size increased (Table I). Following the exposures, fish were transferred to individual aerated recovery tanks.

Total length $\left(L_{\mathrm{T}}\right)$ and mass $(M)$ were monitored throughout the experimental growout period. Each fish was briefly removed from its recovery tank to measure $L_{\mathrm{T}}$ and $M$, and to scan and record the PIT tag number. The $L_{\mathrm{T}}$ and $M$ were tabulated to track changes in individual and group growth and to calculate a $L_{\mathrm{T}}$ and $M$ relationship for the group during the experiment.

To track changes in two-dimensional shape, swimbladder and fish body areas were measured using digital images created from dorsal and lateral radiographs. Relative growth was indexed using lengths of major and minor swimbladder and fish-body axes to calculate elongation values (i.e. minor and major axis). An elongation value of one indicates a circle. As elongation values decrease, the organ is 'stretched' along its sagittal axis. Rates of change in length were compared using allometric growth ratios. Allometric growth ratios $(k)$ are slopes of $\log -\log$ regressions used to compare the relative growth of any two body components, which may include overall length (Huxley, 1932). If the value of $k$ equals one, then both components are growing at the same rate. If $k$ does not equal one, then one component is growing faster than the other. Change in swimbladder development was also monitored by measuring the angle between the

TABLE I. Dates, media type and settings used for Oncorhynchus mykiss radiographs with the XTEC Laseray 90P

\begin{tabular}{|c|c|c|c|c|}
\hline Date & Media type & Intensity $(\mathrm{kVp})$ & Time (s) & Number of fish \\
\hline 22 October 2001 & Redipak & 80 & $2 \cdot 00$ & 35 \\
\hline 29 October 2001 & Redipak & 80 & $2 \cdot 00$ & 34 \\
\hline 19 November 2001 & Redipak & 90 & $2 \cdot 00$ & 32 \\
\hline 03 December 2001 & Redipak & 90 & $2 \cdot 00$ & 31 \\
\hline 17 December 2001 & Redipak & 90 & $2 \cdot 00$ & 31 \\
\hline 04 January 2002 & Redipak & 90 & $2 \cdot 00$ & 31 \\
\hline 14 January 2002 & Redipak & 90 & $2 \cdot 00$ & 30 \\
\hline 28 January 2002 & Redipak & 90 & $2 \cdot 00$ & 30 \\
\hline 7 February 2002 & Redipak & 95 & $2 \cdot 00$ & 29 \\
\hline 25 February 2002 & Redipak & 95 & $2 \cdot 00$ & 29 \\
\hline \multirow[t]{2}{*}{11 March 2002} & Redipak & 95 & $2 \cdot 00$ & 28 \\
\hline & Cassette & 60 & $0 \cdot 12$ & \\
\hline \multirow[t]{2}{*}{1 April 2002} & Redipak & 95 & $2 \cdot 00$ & 28 \\
\hline & Cassette & 70 & $0 \cdot 18$ & \\
\hline \multirow[t]{2}{*}{15 April 2002} & Redipak & 95 & $2 \cdot 00$ & 28 \\
\hline & Cassette & 70 & $0 \cdot 18$ & \\
\hline \multirow[t]{2}{*}{29 April 2002} & Redipak & 95 & $2 \cdot 00$ & 27 \\
\hline & Cassette & 70 & $0 \cdot 18$ & \\
\hline \multirow[t]{2}{*}{15 May 2002} & Redipak & 95 & $2 \cdot 00$ & 26 \\
\hline & Cassette & 70 & $0 \cdot 18$ & \\
\hline \multirow[t]{2}{*}{28 May 2002} & Redipak & 95 & $2 \cdot 00$ & 24 \\
\hline & Cassette & 70 & $0 \cdot 18$ & \\
\hline
\end{tabular}


medial axis of the swimbladder and the sagittal axis of the fish body using the lateral radiograph from each measurement period.

Changes in three-dimensional shape were monitored using swimbladder and fish body volumetric measurements derived from lateral and dorsal radiographs. Paired, digitized outlines of the swimbladder and fish body from each measurement period were elliptically interpolated at $45^{\circ}$ increments to create three-dimensional wireframes with $1 \mathrm{~mm}$ resolution. Both the fish body and swimbladder are represented by sets of contiguous $1 \mathrm{~mm}$ cylinders. Body component volumes were estimated by summing the area of each contiguous cylinder.

To quantify effects of individual growth trajectories on acoustic backscatter, dorsal and lateral radiographs were used to estimate TS values of each fish at each radiograph session. The TS values were calculated using a Kirchhoff-ray mode (KRM) model parameterized for $O$. mykiss in fresh water (Table II). The body is represented by a set of contiguous fluid-filled cylinders surrounding a set of contiguous gas-filled cylinders that represent the swimbladder. Backscatter from each cylinder in the body and the swimbladder is estimated and then added coherently to estimate total backscatter as a function of fish caudal length $\left(L_{\mathrm{C}}, \mathrm{m}\right)$ and acoustic wavelength $(\lambda, \mathrm{m})$. The acoustic wavelength is a function of the speed of sound in water $\left(c, \mathrm{~ms}^{-1}\right)$ and the transmitting frequency $(f, \mathrm{~Hz})$ (i.e. $\left.\lambda=c f^{-1}\right)$. Full details of the model can be found in Clay $\&$ Horne (1994), Jech et al. (1995) and Horne \& Jech (1999). The $L_{C}$ used in backscatter model predictions were converted to $L_{T}$ using a regression developed from the experimental fish: $L_{\mathrm{T}}=1.093 L_{\mathrm{C}}+2.73\left(r^{2}=0.9938, n=384\right)$. To examine the effect of linearly scaling a fish in all dimensions when estimating TS values over a range of lengths, digital images from radiographs from 15 of 16 measurement periods were used to estimate TS of a single fish over a $L_{\mathrm{T}}$ range of $120-320 \mathrm{~mm}$ at 38 and $120 \mathrm{kHz}$. The TS values for each fish were also estimated at the average $L_{\mathrm{T}}$ at each measurement period at 38 and $120 \mathrm{kHz}$. All mean and S.D. were calculated in the linear domain before being transformed to $\log _{10}$ TS values.

To examine if contributions to acoustic reflectivity from factors other than $L_{\mathrm{T}}$ are significant, generalized additive mixed models (GAMM: Lin \& Zhang, 1999; Fahrmeir \& Lang, 2001; Wood, 2006a) were constructed using the multi-general cross-validation (mgcv, version 1.3-27) package in $\mathrm{R}$ ( $\mathrm{R}$ Development Core Team, 2007) to predict TS at 38 and $120 \mathrm{kHz}$ using individual fish as the group variable. A GAMM is a non-parametric regression that contains multiple measures on a group of individuals but inferences can be made on the population if smooth terms are used as random effects. Covariates considered for inclusion in GAMM models included: $L_{\mathrm{T}}$, swimbladder tilt angle, and dorsal and lateral elongation ratios of the fish body. All models were fitted using the Gaussian family and an identity link function. No assumptions of linearity were made for the covariates so each predictor variable was initially represented as a smooth function. A full GAMM was initially fitted for each frequency. Non-significant terms were removed and the model was refitted. An ANOVA was used to compare the fit of the full and reduced models. The best GAMM at each frequency was determined using two criteria: the highest $r^{2}$ value and the lowest Akaike information criterion (AIC) value (Akaike, 1974). The final GAMM model was compared to a GAMM TS model using $L_{\mathrm{T}}$ as the only covariate.

TABLE II. Sound speeds and densities of fish bodies swimbladders and water used in Kirchhoff-ray mode backscatter models

\begin{tabular}{lcc}
\hline Component & Sound speed $\left(\mathrm{m} \mathrm{s}^{-1}\right)$ & Density $\left(\mathrm{kg} \mathrm{m}^{-3}\right)$ \\
\hline Fish body & 1570 & 1080 \\
Swimbladder & 340 & $2 \cdot 64$ \\
Water & 1490 & 1000 \\
\hline
\end{tabular}




\section{RESULTS}

When not being radiographed, fish were held in raceways or tanks at the University of Washington fish hatchery for a total of 218 days from late October 2001 until late May 2002 (Table I). Water temperatures in holding tanks (Fig. 1) paralleled the annual cycle of near-surface temperatures in Lake Washington except for a 2 month period (January to February) when heated water was added to enhance fish growth. Water temperatures rapidly decreased from a high of near $17^{\circ} \mathrm{C}$ in October to a low of $9^{\circ} \mathrm{C}$ by mid-December. Water temperature slowly increased and reached $15^{\circ} \mathrm{C}$ by the following June.

Twenty-four of the 35 fish that were initially PIT tagged survived through 16 rounds of radiographs (Table I). Data from fish that did not survive the 16 rounds of radiographs were excluded from all analyses. PIT tags remained in gut cavities for the duration of the experiment. Both PIT tags and swimbladders were visible in dorsal and lateral radiographs as each fish grew (Fig. 2). To provide a baseline example of individual growth, a random fish (PIT tag: 023 317 030) (Fig. 2) was selected and used as an example for subsequent figures. Swimbladders of all fish remained inflated for the duration of the experiment.

Despite the seasonal cooling and warming of water in holding tanks, $L_{\mathrm{T}}$ increased at a near constant rate throughout the duration of the experiment. This pattern was consistent for each individual and for the group (Fig. 3). Average $L_{\mathrm{T}}$ increased almost $1.37 \mathrm{~mm} \mathrm{day}^{-1}\left(L_{\mathrm{T}}=109.64+1.37 x-0.001 x^{2}\right.$, where $x=$ day; $\left.n=16, r^{2}=0.997\right)$. The growth trajectory of the example fish was below the mean of the group. Overall, average $L_{\mathrm{T}}$ increased $256 \mathrm{~mm}$ from the start $(107 \mathrm{~mm})$ to the final $(363 \mathrm{~mm})$ round of radiographs. Variance in $L_{\mathrm{T}}$ among individuals increased with the mean $L_{\mathrm{T}}$ of the group. Growth rates averaged $1 \cdot 18 \mathrm{~mm} \mathrm{day}^{-1}$ over the 218 day measurement period.

Individual and group $M$ also increased during the experiment. A polynomial regression fit to the 24 surviving fish (Fig. 4) predicts a daily increase in $M$ of

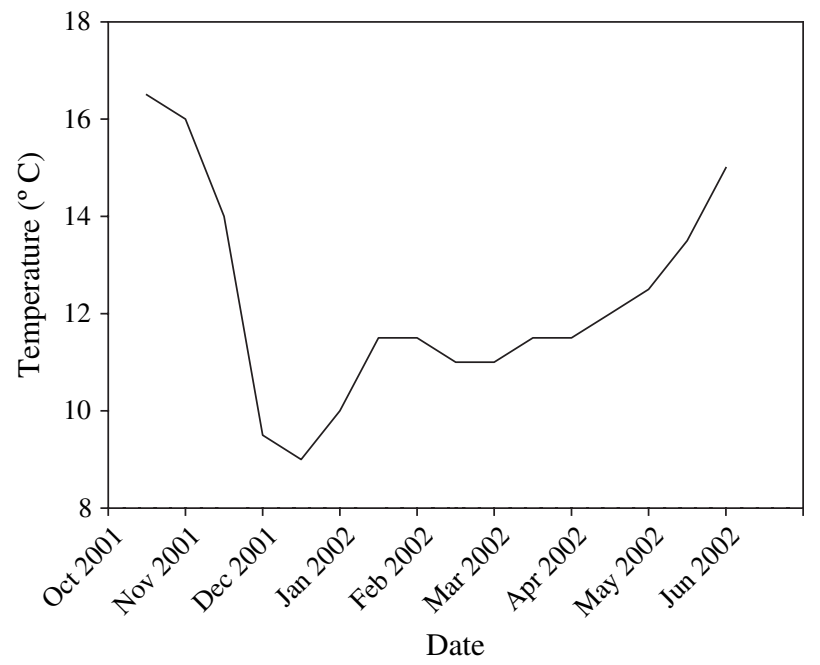

FIG. 1. Water temperature in University of Washington fish hatchery holding tanks during the experiment. 
(a)

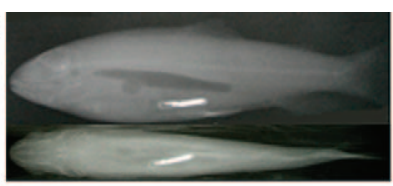

(b)

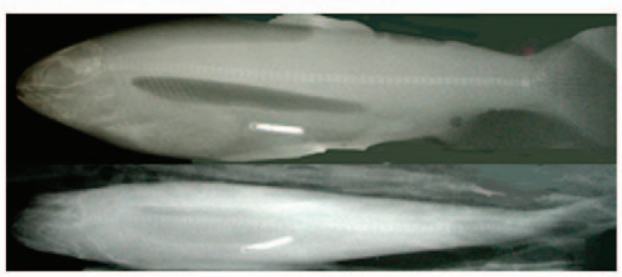

(c)

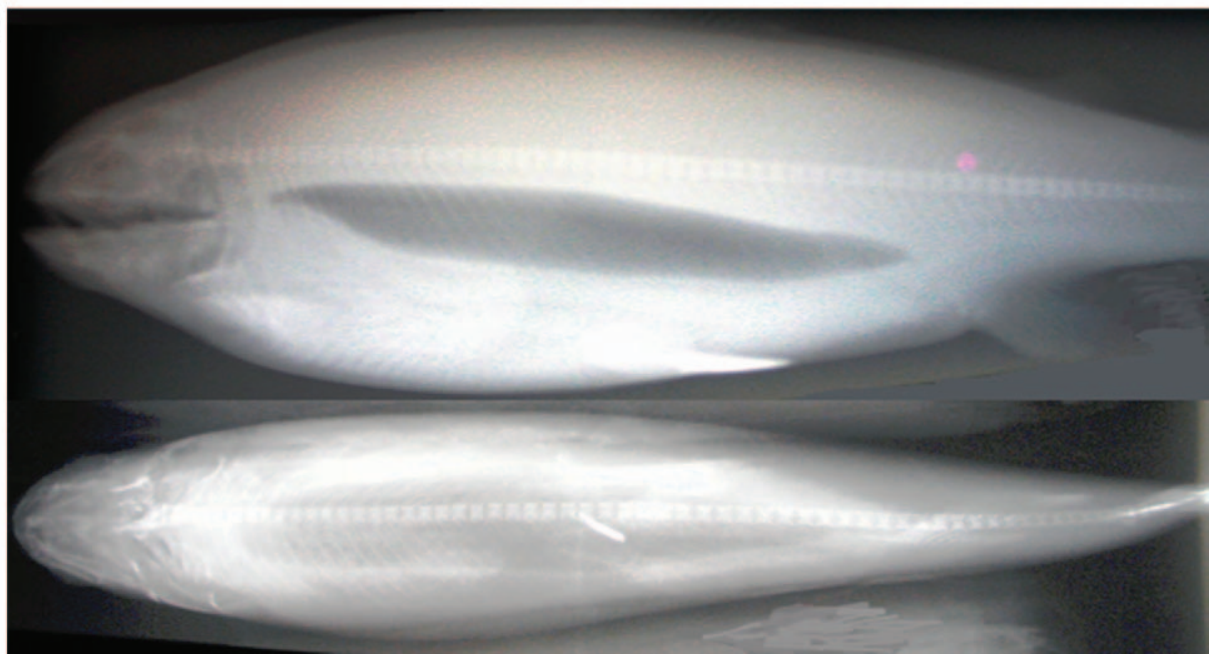

FIG. 2. Oncorhynchus mykiss lateral (upper) and dorsal (lower) radiographs taken from the same fish at (a) round 2 (of 16 rounds) of radiographs $-106.5 \mathrm{~mm}$ total length $\left(L_{\mathrm{T}}\right)$, (b) round $5-170 \mathrm{~mm} L_{\mathrm{T}}$ and (c) round $15-333 \mathrm{~mm} L_{\mathrm{T}}$. The swimbladder is the dark organ below the spinal column. The passive integrated transponder (PIT) tag is visible below the swimbladder.

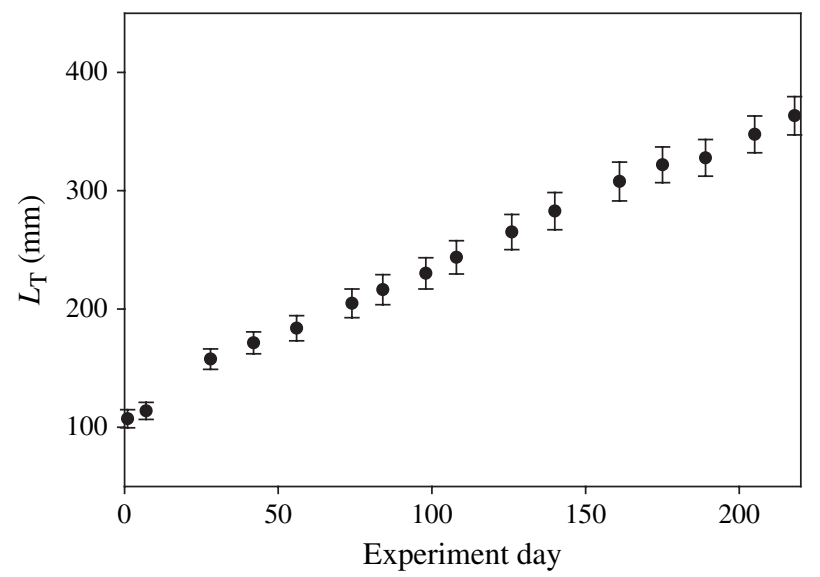

FIG. 3. Mean \pm S.D. total length $\left(L_{\mathrm{T}}\right)$ of Oncorhynchus mykiss at each measurement period. 


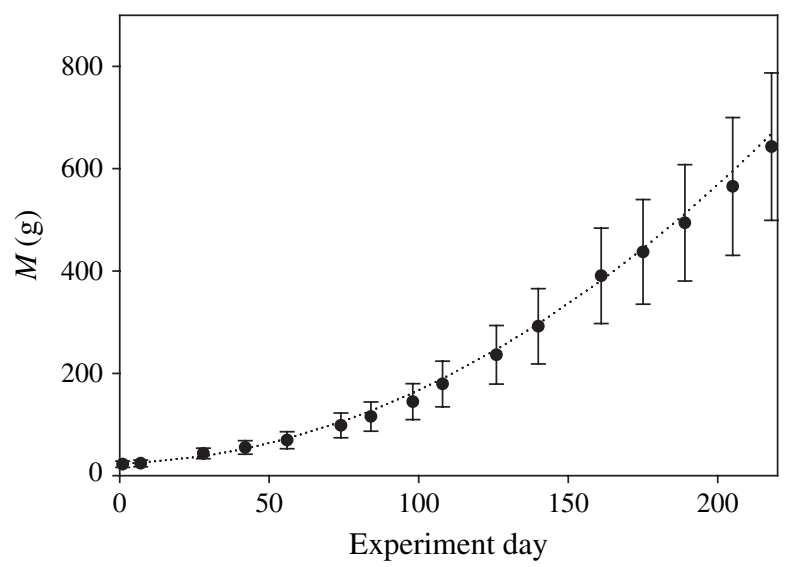

Fig. 4. Mean \pm S.D. mass $(M)$ of Oncorhynchus mykiss at each measurement period. The curve was fitted by a polynomial regression equation [shown for the group growth trajectory $(\cdots): y=23 \cdot 38+0 \cdot 15 x$ $\left.+0 \cdot 001 x^{2}\left(n=16, r^{2}=0 \cdot 998\right)\right]$.

$0.15 \mathrm{~g} \mathrm{~g}^{-1} \mathrm{day}^{-1}$ and an average $M$ gain of $2.95 \mathrm{~g} \mathrm{day}^{-1}$ over the experimental period. The $M$ gain in the example fish initially matched that of the group until the day 28 and was less than average during the remainder of the grow out period. Using average $L_{\mathrm{T}}$ and $M$ from 16 rounds of radiographs (Fig. 5), the In relationship between mean $L_{\mathrm{T}}$ and $M$ indicated that $M$ scaled approximately with the volume of the fish (i.e. $L_{\mathrm{T}}^{3}$ ).

Dorsal swimbladder surface areas of each individual and the group increased over time. Areas varied among individuals and became more variable overall as fish grew [Fig. 6(a)]. Dorsal swimbladder area variability as a function of $L_{\mathrm{T}}$, measured using coefficients of variation (c.v.), differed by a factor of two and was greatest from experimental days 50 to 140 [Fig. 6(b)]. A quadratic regression was used to characterize changes in mean dorsal swimbladder surface areas of the group over the experimental period [Fig. 6(b)]. Shapes of

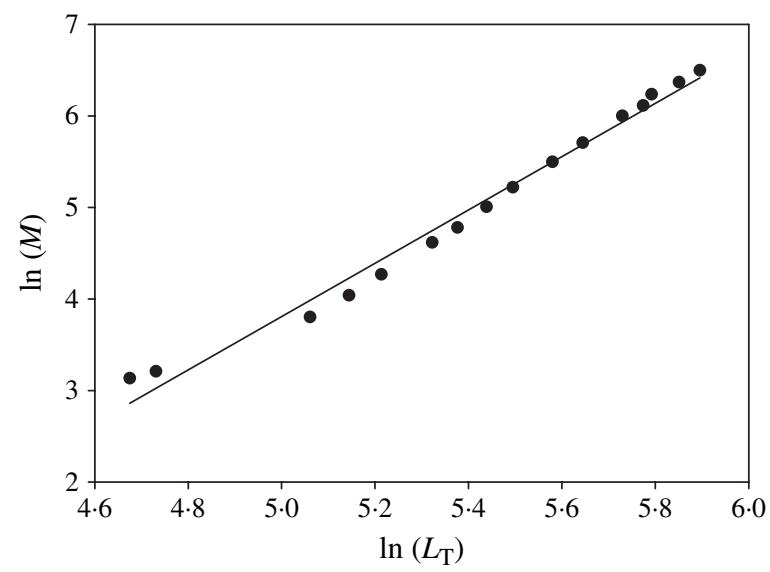

FIG. 5. Mean In total length $\left(L_{\mathrm{T}}\right)$ and mass relationship for 24 Oncorhynchus mykiss over the 218 day experimental period. The curve was fitted by: $y=-10 \cdot 75+2.91 x\left(n=16, r^{2}=0.98\right)$. 


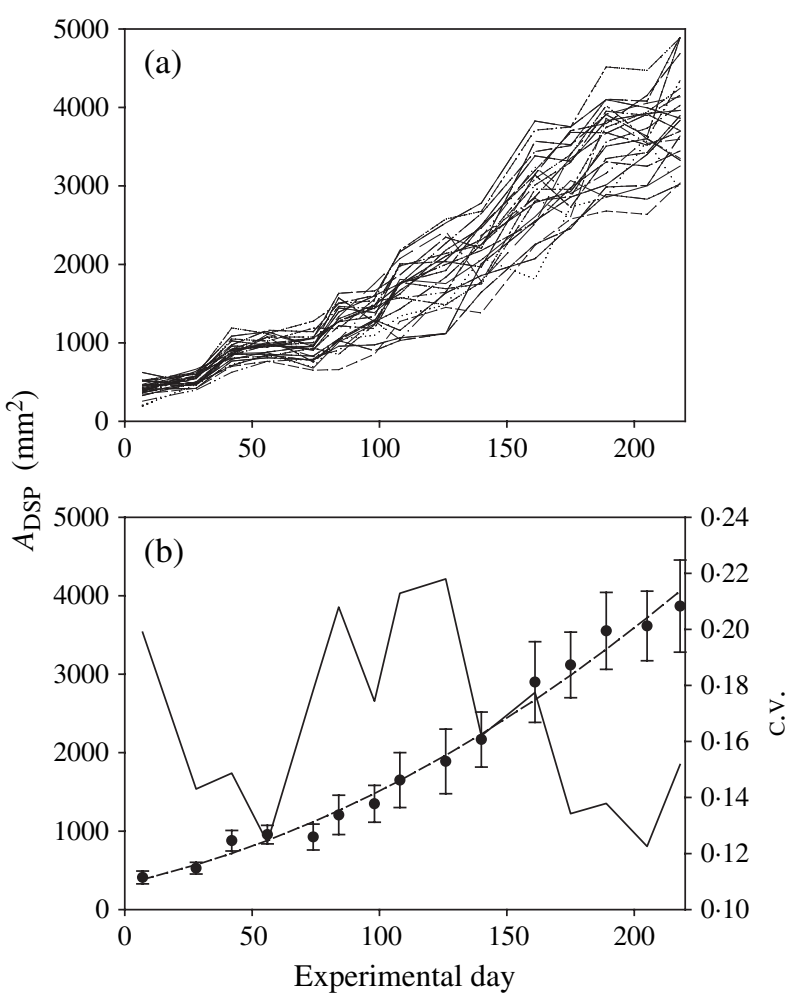

FIG. 6. Dorsal swimbladder surface area $\left(A_{\mathrm{DSB}}\right)$ of (a) 24 Oncorhynchus mykiss obtained from radiographs and (b) mean \pm S.D. $A_{\mathrm{DSB}}$ of the group with the corresponding coefficients of variation (C.V., and quadratic regression curve: $y=328 \cdot 360+7 \cdot 330 x+0 \cdot 045 x^{2}\left(n=16\right.$, adjusted $\left.r^{2}=0 \cdot 984\right)(---)$, over the 218 day experimental period.

swimbladders and fish bodies varied among individual $O$. mykiss at each measurement session and through the experimental period. Average swimbladder lateral elongation ratio values were consistently less than but close to dorsal values (Fig. 7). Lateral swimbladder elongation values remained constant after the fifth round of radiographs (i.e. experimental day 56). Dorsal swimbladder elongation values tended to decrease as swimbladders grew. A small increase in mean dorsal swimbladder elongation values was observed between measurement rounds 11 and 12. All elongation values were $<1$, indicating that growth in length exceeded that in width. In contrast, average fish-body lateral elongation values exceeded dorsal values (Fig. 7). The spread between the dorsal and lateral body ratios was greater than that observed among dorsal and lateral swimbladder ratio values. Dorsal elongation values remained constant across all experimental measurements. The traditional cylindrical fish shape was maintained in fish body and swimbladder dorsal planes with minor axes being $c .<20 \%$ the length of major axes throughout the experiment. Average swimbladder length increased with $L_{\mathrm{T}}$ [Fig. 8(a)]. The allometric growth ratio of swimbladder to $L_{\mathrm{T}}$ based on all individual fish measurements [Fig. 8(b)] was $1 \cdot 187$ (C.v. $=0 \cdot 686, n=358$, $\left.r^{2}=0.984, P<0.001\right)$, indicating that swimbladders were growing $19 \%$ faster on average than $L_{\mathrm{T}}$. To characterize the rate of change in swimbladder shape 


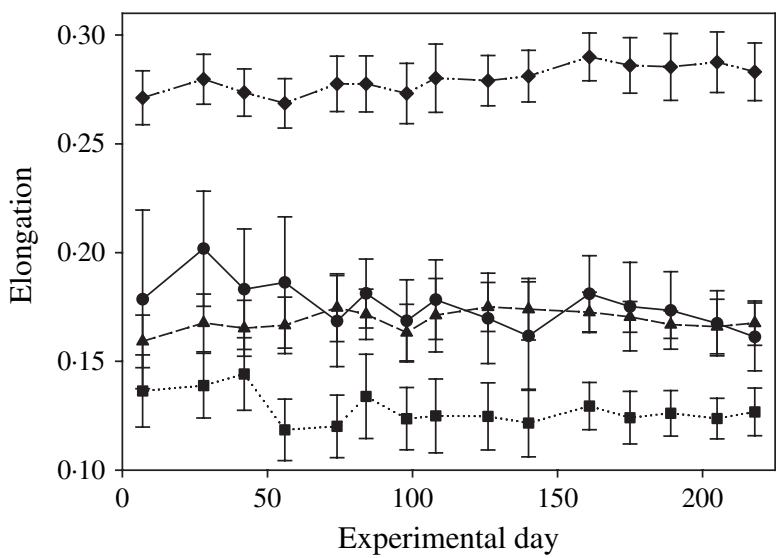

FIG. 7. Mean \pm S.D. elongation values of 24 Oncorhynchus mykiss at each measurement period for the dorsal

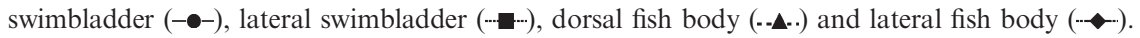
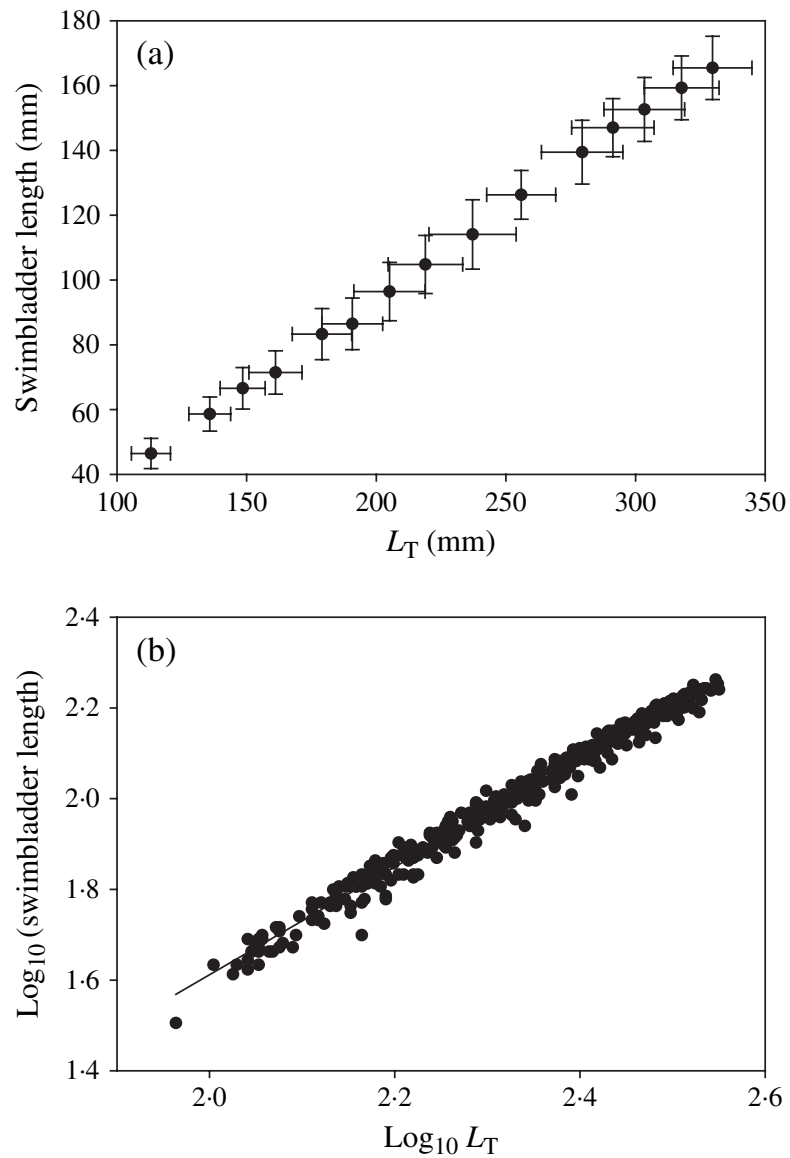

FIG. 8. (a) Group mean \pm S.D. of Oncorhynchus mykiss swimbladder length plotted as a function of fish total length $\left(L_{\mathrm{T}}\right)$ at each measurement period and (b) allometric growth ratio of swimbladder to fish body, $k=1.187\left(r^{2}=0.984, P<0.001, n=358\right)$. 
relative to the rate of change in $L_{\mathrm{T}}$, allometric growth ratios were calculated using dorsal and lateral swimbladder elongation ratios relative to $L_{\mathrm{T}}$. In both cases, $L_{\mathrm{T}}$ increased faster than changes in elongation values (lateral swimbladder elongation: $-0 \cdot 094, r^{2}=0 \cdot 058, P<0 \cdot 001, n=358$; dorsal swimbladder elongation: $\left.-0 \cdot 117, r^{2}=0 \cdot 057, P<0 \cdot 001, n=358\right)$. The negative, low values indicate that swimbladders became more cylindrical as $L_{\mathrm{T}}$ increased.

Swimbladder angles also changed through the course of the experiment. Swimbladder angles for most fish generally increased at each successive measurement [Fig. 9(a)]. This trend was reflected in the group mean [Fig. 9(b)], with a shift in mean swimbladder angle from 80 to $86^{\circ}$ between the start and the end of the experiment. A non-significant decrease $\left(0.67^{\circ}\right)$ in mean swimbladder angle occurred between the 10th and the 11 th round of measurements at experimental day 140 when mean $L_{\mathrm{T}}$ was $283 \mathrm{~mm}$.

Swimbladder volumes increased exponentially through the experiment [Fig. 10(a)]. Variance among individuals increased in proportion to the mean swimbladder volume [Fig. 10(b)]. Mean volumes increased $>27$-fold from

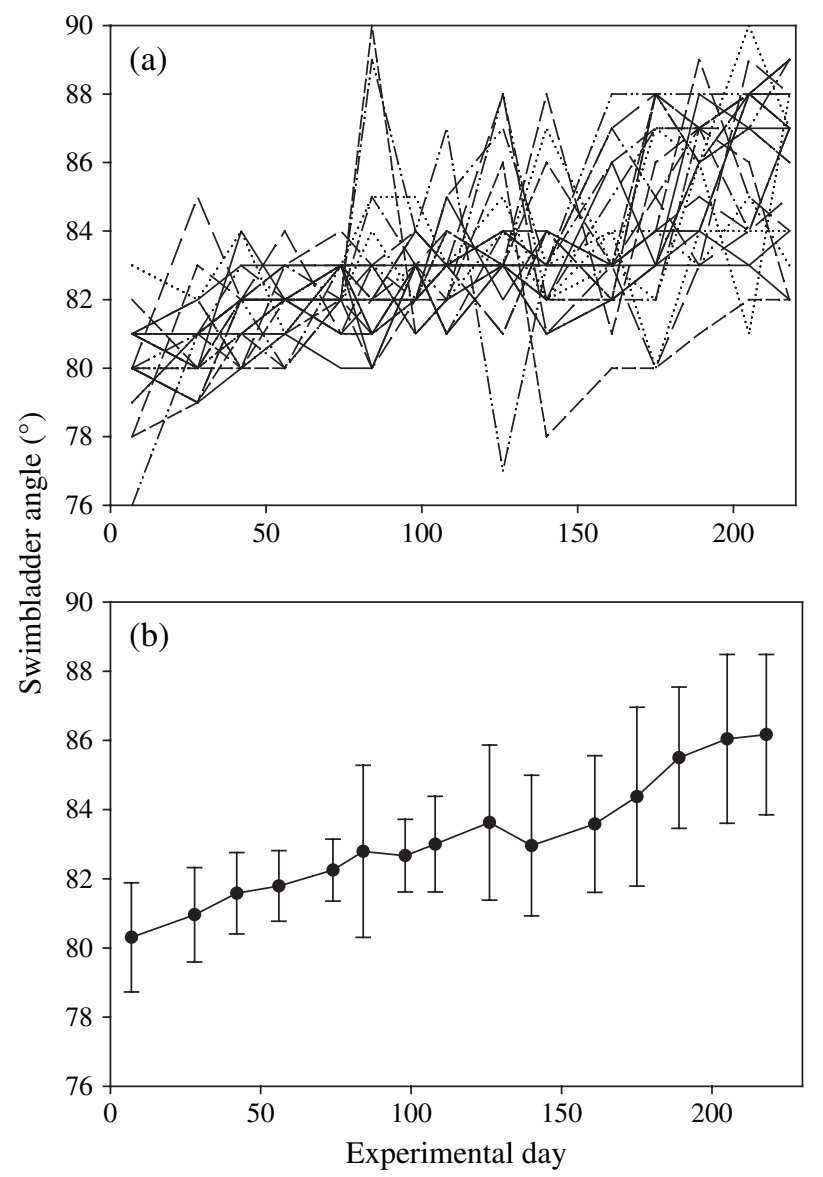

FIG. 9. Angle of swimbladder relative to Oncorhynchus mykiss sagittal axis for (a) all fish and (b) the mean \pm S.D. of the group at each measurement period. 
$1206 \mathrm{~mm}^{3}$ at day 7 to $32971 \mathrm{~mm}^{3}$ at the end of the experiment (day 218). Despite variation among individuals, a 'jump' in mean swimbladder volumes occurred between measurement rounds 11 and 12. Ratios of individual swimbladder to fish body volumes tended to increase but did not exceed $8 \%$ over the experimental period [Fig. 11(a)]. Mean ratio values fluctuated between 0.045 and 0.055 with large variability at each measurement period [Fig. 11(b)]. Swimbladder growth was rapid relative to fish-body growth over the first three measurement periods. Consistent with changes in swimbladder volumes, an increase in swimbladder to fish-body volume ratio value was observed between the 11th and the 12th measurement rounds.

Predicted TS of the example fish at any $L_{\mathrm{T}}$ differed depending on the initial $L_{\mathrm{T}}$ of the fish used to estimate acoustic reflectivity. If growth of an individual fish was linear in all dimensions, then TS at any $L_{\mathrm{T}}$ from all measurement rounds were predicted to be equal. To illustrate how ontogeny affects acoustic reflectivity, TS were predicted at 38 [Fig. 12(a)] and $120 \mathrm{kHz}$ [Fig. 12(b)] at a $\mathrm{mm}$ resolution for 14 radiograph sessions over a $L_{\mathrm{T}}$ range of $120-320 \mathrm{~mm}$. For each set of backscatter predictions, fish bodies and swimbladders were proportionately scaled in all dimensions across the $L_{\mathrm{T}}$ range. The predicted TS at

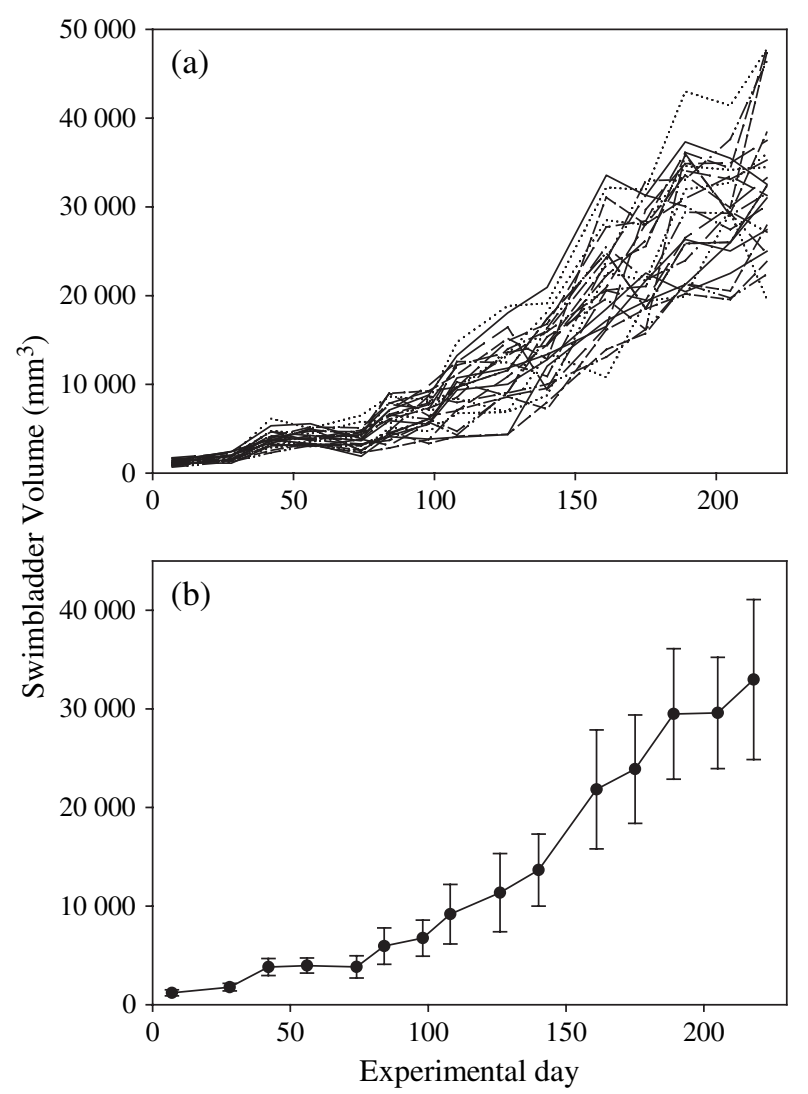

FIG. 10. Oncorhynchus mykiss swimbladder volumes of (a) each fish and (b) the mean \pm S.D. of the group at each measurement period. 


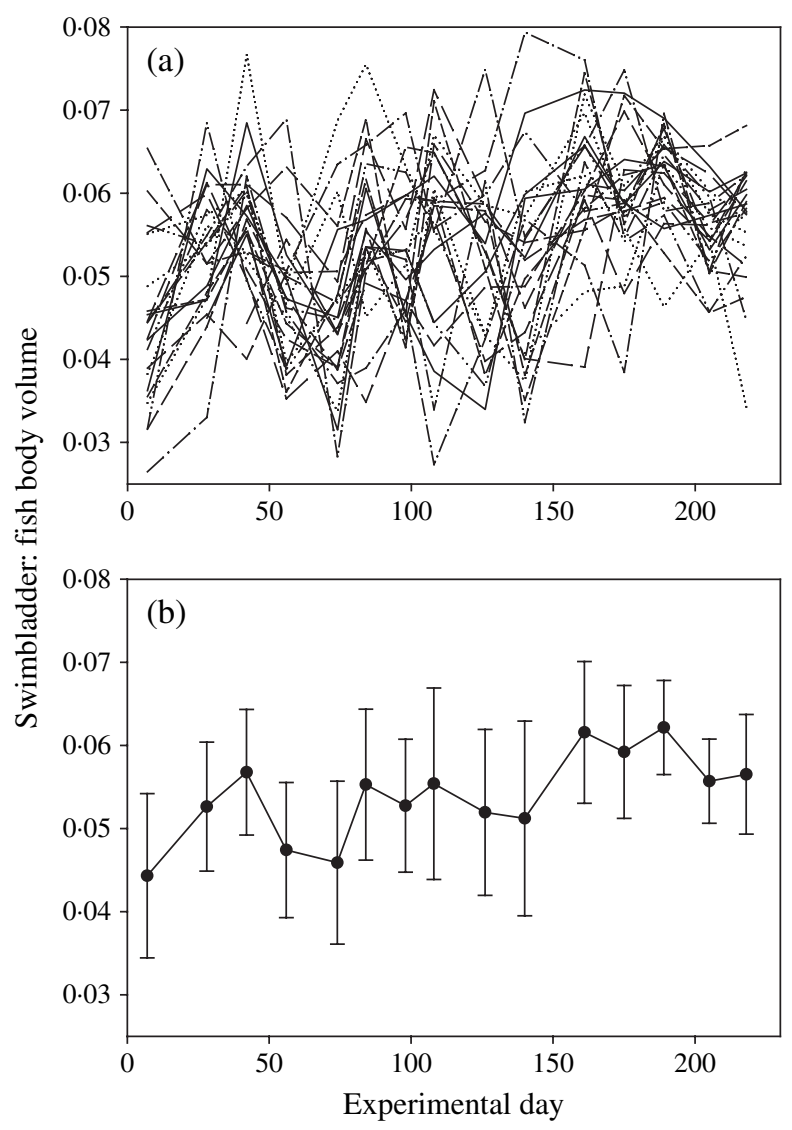

FIG. 11. Swimbladder to fish body volume ratios of Oncorhynchus mykiss for (a) each fish and (b) the mean \pm S.D. of the group at each measurement period.

the observed $L_{\mathrm{T}}$ from that measurement period are indicated (Fig. 12). As expected, the range of predicted TS at each $L_{\mathrm{T}}$ was lower at $38 \mathrm{kHz}$ than at 120 $\mathrm{kHz}$. At $38 \mathrm{kHz}$, the variability of predicted TS increased at longer $L_{\mathrm{T}}$. Variability among TS at $120 \mathrm{kHz}$ was larger at any $L_{\mathrm{T}}$ than at $38 \mathrm{kHz}$ and across the entire $L_{\mathrm{T}}$ range. Variability in TS using observed fish $L_{\mathrm{T}}$ was lower between measurement rounds than at any individual measurement round using scaled $L_{\mathrm{T}}$. Despite $k$ values being close to unity, $L_{\mathrm{T}}$ influenced predicted TS when $L_{\mathrm{T}}$ were proportionately scaled over a range of lengths.

Mean, predicted acoustic backscatter increased at both 38 and $120 \mathrm{kHz}$ as mean $L_{\mathrm{T}}$ increased from radiograph rounds 2 to 16 (Fig. 13). With the exception of round 7 ( $t$-test, d.f. $=46, P<0.05)$, TS at $38 \mathrm{kHz}$ significantly exceeded those at $120 \mathrm{kHz}$ until radiograph round 11 , which was not significant ( $t$-test, d.f. $=$ $46, P>0.05)$. TS values at $120 \mathrm{kHz}$ exceeded but were not significantly different from those at $38 \mathrm{kHz}$ from 283 until $363 \mathrm{~mm}$. The change in relative TS amplitudes at $283 \mathrm{~mm}$ coincided with increases in swimbladder angle [Fig. 9(b)] and in the ratio of swimbladder to fish body volume [Fig. 11(b)]. Backscatter was more variable among fish within the group at $120 \mathrm{kHz}$ than at $38 \mathrm{kHz}$. 


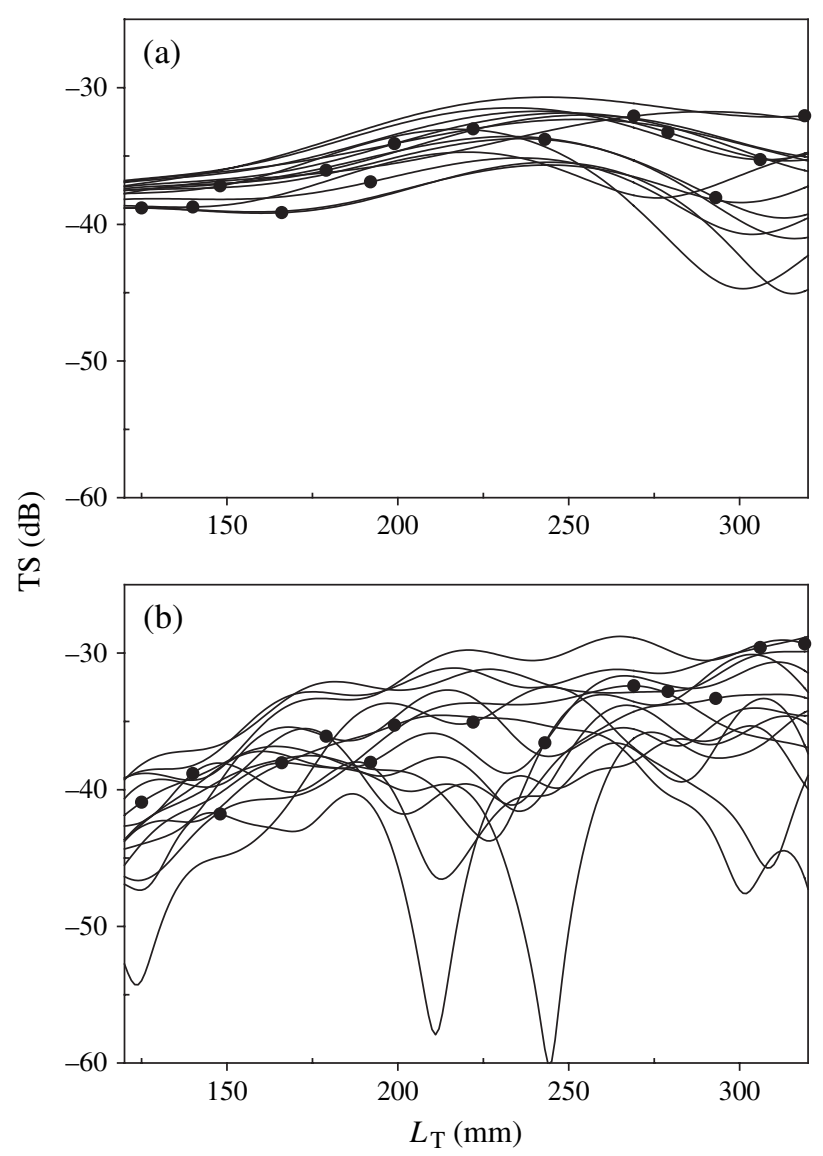

FIG. 12. Predicted target strengths (TS) of the example Oncorhynchus mykiss at (a) 38 and (b) $120 \mathrm{kHz}$ over a total length $\left(L_{\mathrm{T}}\right)$ range of $120-320 \mathrm{~mm}$ using the radiographs from each measurement period. the predicted TS of the fish at each measurement period.

To be consistent with empirical TS $(y)$ to $L_{\mathrm{T}}$ conversion equations, regressions were fitted to the 38 and $120 \mathrm{kHz}$ predicted backscatter curves. When slopes were fixed at 20 (Foote, 1980a), regression intercept values differed between frequencies by $c .2 \cdot 5 \mathrm{~dB}:-62 \cdot 6$ at $38 \mathrm{kHz}\left(r^{2}=0 \cdot 15, n=15\right)$ and -65 at $120 \mathrm{kHz}$ $\left(r^{2}=0 \cdot 82, n=15\right)$. When slopes were allowed to 'float', regression equation fits improved at both frequencies: $y=10.75 \log _{10} L_{\mathrm{T}}-49.80\left(r^{2}=0.58\right.$ at $38 \mathrm{kHz}$, $n=15) ; y=25 \cdot 26 \log _{10} L_{\mathrm{T}}-72 \cdot 26\left(r^{2}=0.86\right.$ at $\left.120 \mathrm{kHz}, n=15\right)$.

All covariates except dorsal fish body elongation ratio were significant in final 38 (adjusted $r^{2}=0 \cdot 64, n=358$ ) and 120 (adjusted $r^{2}=0 \cdot 37, n=358$ ) $\mathrm{kHz}$ GAMMs (Table III). Intercept values of final models were -36.44 at 38 and -39.47 at $120 \mathrm{kHz}$ (both $t$-test, $P<0.001$ ). In the $120 \mathrm{kHz}$ multiple covariate model, swimbladder angle and lateral fish-body elongation ratio were fitted as linear factors. An additional multi-covariate GAMM model at $120 \mathrm{kHz}$ fitting swimbladder angle and lateral body-elongation ratio as linear terms, did not improve the fit of the model $\left(r^{2}=0 \cdot 37, n=358\right)$. Plots of smooths showed that all variables at $120 \mathrm{kHz}$ had TS values that increased with an increase in 


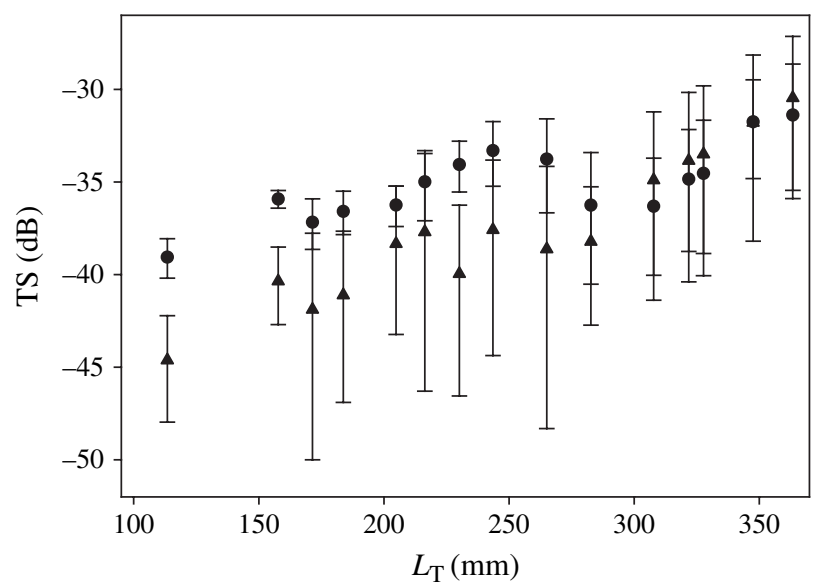

FIG. 13. Predicted mean \pm s.D. target strength (TS) of 24 Oncorhynchus mykiss at 38 as a function of total fish length $\left(L_{\mathrm{T}}\right)$.

each variable. This pattern was also observed and was stronger at $38 \mathrm{kHz}$ for swimbladder angle. At $38 \mathrm{kHz}$, the effect of $L_{\mathrm{T}}$ varied about the mean TS over the range of $L_{\mathrm{T}}$ included in the regression. Lateral fish body elongation ratio only differed from the mean $>0.30$ at $38 \mathrm{kHz}$. ANOVA comparisons of multiple covariate to $L_{\mathrm{T}}$ only GAMM models showed that multiple-term models were a better fit to the data at $38(\mathrm{AIC}=1591 \cdot 37, P<0.001)$ and $120(\mathrm{AIC}=$ 2106.62, $P<0 \cdot 001) \mathrm{kHz}$.

\section{DISCUSSION}

The combination of terms acoustic and ontogeny is not normally associated with reflection of sound from fishes. Acoustic ontogeny is traditionally used to characterize hearing development and sound production in aquatic vertebrates such as fishes (Wysocki \& Ladich, 2001; Amorim \& Hawkins, 2005), seals (Charrier et al., 2001) and dolphins (McCowan \& Reiss, 1995). In this study,

TABLE III. Approximate significance of smooth terms in final generalized additive mixed models (GAMM) of predicted target strength (TS) as a function of fish total length $\left(L_{\mathrm{T}}\right)$, swimbladder angle $(\theta)$, and fish-body lateral (ellatbody) and dorsal (eldorbody) elongation ratios at 38 and $120 \mathrm{kHz}$

\begin{tabular}{|c|c|c|c|c|c|c|}
\hline \multirow[b]{2}{*}{ Variable } & \multicolumn{2}{|c|}{ edf } & \multicolumn{2}{|c|}{$F$} & \multicolumn{2}{|c|}{$P$} \\
\hline & 38 & 120 & 38 & 120 & 38 & 120 \\
\hline$L_{\mathrm{T}}$ & $6 \cdot 83$ & $3 \cdot 47$ & $12 \cdot 20$ & $4 \cdot 29$ & 0 & 0 \\
\hline$\theta$ & $7 \cdot 29$ & $1 \cdot 00$ & $24 \cdot 12$ & $28 \cdot 49$ & 0 & \\
\hline Ellatbody & $5 \cdot 26$ & $1 \cdot 00$ & $4 \cdot 70$ & 6.98 & 0 & $0 \cdot 001$ \\
\hline Eldordody & NS & NS & & & & \\
\hline
\end{tabular}

edf, effective d.f. (Wood, 2006a).

NS, non-significant $(P>0 \cdot 05)$. 
acoustic ontogeny is used to characterize morphological changes that influence the intensity of backscattered sound. Morphological changes potentially include alteration of material properties and changes in size or shape of structures that reflect sound. The definition of material properties in this study is limited to density $(\rho)$ and the speed of sound $(c)$ of scattering organs, and whose product defines the acoustic impedance (i.e. $z=\rho c$ ). The proportion of sound reflected at the interface of any two structures depends on the difference between the two acoustic impedances. The larger the difference in acoustic impedances, the more reflected sound. The largest acoustic impedance difference in a fish occurs at the interface of flesh and a gas-filled swimbladder. In addition to obvious differences among tissues, densities of structures can differ during growth of an individual animal (Horne \& Jech, 2005).

Interindividual and intraindividual growth differed among $O$. mykiss used in this experiment. Changes in $L_{\mathrm{T}}$ and $M$ of $O$. mykiss are faster than in many other salmonid species (Barton, 1996). The $L_{\mathrm{T}}$ attained during this experiment were equivalent to mean $L_{\mathrm{T}}$ of 2 year-old fish when compared to seven freshwater salmonid species (Carlander, 1969). Individuals from natural O. mykiss populations mature in 4 years and weigh $c$. $0.68 \mathrm{~kg}$. Oncorhynchus mykiss (hybrid) mature in 2 years and can weigh as much as $4.5 \mathrm{~kg}$ (Donaldson, 1968). Consistent with other fish species, conventional ( $L_{\mathrm{T}}$ and $M$ ) and acoustically relevant (swimbladder surface area and swimbladder volume) growth metrics increased with $L_{\mathrm{T}}$. Over the grow out period, average swimbladder dorsal surface area increased $9 \cdot 5$ times (from $408 \cdot 7$ to $3867 \cdot 6 \mathrm{~mm}^{2}$ ) with the range of areas at the last radiograph round spanning over $1850 \mathrm{~mm}^{2}$ (i.e. $3036 \cdot 3$ to $4887 \cdot 1 \mathrm{~mm}^{2}$ ). The corresponding increase in swimbladder volume exceeded 27 -fold with the group average increasing from $1206 \cdot 2$ to $32971 \cdot 5 \mathrm{~mm}^{3}$. By the end of the experiment, swimbladder volumes ranged over a factor of two (22 401.5-47 782.8 $\mathrm{mm}^{3}$ ). Despite average changes in swimbladder surface areas and volumes, the proportion of swimbladder volume as a fraction of body volume remained fairly constant, between 4 and $6 \%$. This fraction is well within the range cited for marine and freshwater fishes (Alexander, 1966; Sand \& Hawkins, 1973; Harden Jones \& Scholes, 1985).

Differences in shape and size of swimbladders have large potential impacts on the amount of energy reflected from a fish as it grows. The largest change in acoustic ontogeny will occur at first inflation of the swimbladder (McEwen, 1940; Schwarz, 1971). Swimbladder first inflation ranges from 3 to 15 days depending on species and temperature (Doroshev et al., 1981; Bailey \& Doroshev, 1995). Haslett (1962) and Foote (1980a) have shown that the swimbladder contributes a minimum of $90 \%$ to the backscatter from swimbladdered fishes, which includes $O$. mykiss. To illustrate the acoustic contribution of the swimbladder using the example fish at a $L_{\mathrm{T}}$ of $333 \mathrm{~mm}$, TS values were reduced by $9.3 \mathrm{~dB}$ re $1 \mu \mathrm{Pa}$ at $38 \mathrm{kHz}$ and $21.7 \mathrm{~dB}$ re $1 \mu \mathrm{Pa}$ at $120 \mathrm{kHz}$ when the swimbladder was removed from model calculations. Any change in swimbladder angle during development will have the second largest effect on acoustic backscatter. A reduction (i.e. towards horizontal) in mean tilt angle of $6^{\circ}$ within the group was observed between the start and the end of the experiment. Although not a direct comparison if the angle of the swimbladder was reduced by $6^{\circ}$ in the example fish, the predicted TS at $38 \mathrm{kHz}$ increases by $8.8 \mathrm{~dB}$ re $1 \mu \mathrm{Pa}$ at 
a $L_{\mathrm{T}}$ of $333 \mathrm{~mm}$. The third major factor influencing acoustic backscatter is change in swimbladder surface areas and shapes. Among O. mykiss, swimbladder dorsal surface areas increased by the square of $L_{\mathrm{T}}$. To provide a comparison, dorsal swimbladder surface areas as a function of $L_{\mathrm{T}}$ were linearly modelled for walleye pollock Theragra chalcogramma (Pallas) (Horne, 2003), although the regression fit would improve if a quadratic function were used within the caudal length range of 100-400 mm. Oncorhynchus mykiss mean TS did not scale proportionately to increases in dorsal swimbladder surface area at 38 or $120 \mathrm{kHz}$, which was used as a proxy for acoustic backscattering cross-section. Changes in swimbladder shape were characterized using elongation ratios (i.e. ratios of minor to major axes). Dorsal swimbladder elongation ratio values exceeded lateral values throughout the experimental period and decreased as fish grew. Lateral swimbladder elongation ratio values were less than comparable values from T. chalcogramma, Pacific herring Clupea pallasii Valenciennes and capelin Mallotus villosus (Müller) of similar lengths (Gauthier \& Horne, 2004), indicating that $O$. mykiss swimbladders are more elliptical relative to the other species. As suggested by changes in shape, rates of change in swimbladder volumes were not constant. Mean volumes increased exponentially over time with an increasing ratio of swimbladder to fish body volume.

Any developmental change that alters the shape or angle of the swimbladder will change the TS of a fish. At geometric scattering frequencies (i.e. when $L_{\mathrm{T}}$ exceed acoustic wavelengths), swimbladder surface area largely determines the amount of energy reflected by a fish. These conditions led Foote (1980a) to suggest setting the slope of the TS $(y)$ to $L_{\mathrm{T}}$ regression equations to 20: $y=10 \log _{10}\left(L_{T}^{2}\right)+a=20 \log _{10}\left(L_{T}\right)+a$, where $a$ is the intercept. This approach facilitates comparison among species using regression intercepts, but large residuals from empirical regression equations prompted McClatchie et al. (1996, 2003) to discourage the use of 20 as an arbitrary slope value. An arbitrary slope regression may not be appropriate for all species (Gauthier \& Horne, 2004), all life-history stages (Horne, 2003) or even within life-history stages (Abe et al., 2004). The fit of the 38 and $120 \mathrm{kHz}$ fixed and floating slopes for O. mykiss also illustrate the point. Jørgensen (2003) found that for M. villosus, a better relationship existed between swimbladder length and TS than between TS and $L_{\mathrm{T}}$. The switch in relative mean backscatter amplitudes at 38 and $120 \mathrm{kHz}$ among O. mykiss corresponded to shifts in swimbladder angle and shape. A similar shift in TS among juvenile T. chalcogramma is the only other documented example (Abe et al., 2004, 2005) of an allometric ontogenetic effect on acoustic backscatter.

Allometric growth by individual animals will decrease accuracy of TS to $L_{\mathrm{T}}$ conversions used in acoustic-based abundance estimates. Data used to quantify species-specific relationships between TS and fish length are acquired using in situ TS measurements from animals in low-density aggregations (Burczynski et al., 1987), or by measuring backscatter from tethered (Nakken \& Olsen, 1977; Horne et al., 2000) or caged (Edwards \& Armstrong, 1984) individuals of known lengths. These methods provide snapshots of TS characteristics from groups of animals but do not track development among individuals. Tracking fish ontogeny was facilitated by PIT tagging each animal using a sample from a cohort. Non-linear changes in growth trajectories of fish swimbladders and 
bodies have been documented for fish cohorts (Abe et al., 2004) or species (Butler \& Pearcy, 1972) but are rarely quantified for individual fishes. Application of TS to fish length regressions across life-history stages or the proportionate scaling of fish bodies and swimbladders without determining allometric growth constants may invalidate TS predictions when used over extended length ranges. Using T. chalcogramma as an example, Abe et al. (2005) derived a different intercept in the average TS and length relationship among juvenile fish (50 to 200 $\mathrm{mm}$ fork length, $L_{\mathrm{F}}$ ) compared to that used in the regression equation based on adult fish (Foote \& Traynor, 1988). Differences in the two equations may result from observed changes in growth ratios (i.e. $k$ values) between swimbladder length and $L_{\mathrm{F}}$ at $L_{\mathrm{F}}>100 \mathrm{~mm}$. Within juvenile $T$. chalcogramma, the reduction in slope of dorsal swimbladder area to $L_{\mathrm{F}}$ ratios occurred at $L_{\mathrm{F}}>100 \mathrm{~mm}$ (Abe et al., 2004, 2005). Among O. mykiss, the growth ratio of swimbladder length to $L_{\mathrm{T}}$ indicated that growth was nearly isometric over the observed $L_{\mathrm{T}}$ range, and that proportionate scaling of fish bodies and swimbladders used in backscatter modelling was appropriate. Based on the simple comparison of growth ratios in $T$. chalcogramma and $O$. mykiss, acoustic ontogeny should be considered species specific, as allometric growth may be restricted to early life-history stages.

Ontogeny was linear throughout the $L_{\mathrm{T}}$ range examined for $O$. mykiss for most acoustically relevant variables. Relevant acoustic variables include swimbladder shape, tilt and dorsal surface area. Swimbladder elongation and $k$ values were near constant through the experimental period indicating that changes in swimbladder shape were linear. A slight non-linear shift was observed among swimbladder mean tilt angles but this shift was not significant. The only factor exhibiting non-linear increase was mean dorsal swimbladder area. At $L_{\mathrm{T}}<200 \mathrm{~mm}$, swimbladder increases in dorsal surface area were exponential. Resulting TS increased with $L_{\mathrm{T}}$ but backscattering curves were not linear, or monotonic, at 38 or $120 \mathrm{kHz}$. Traditional TS and $L_{\mathrm{T}}$ regression equations fitted better when slopes were allowed to float. The non-linear increase in TS with $L_{\mathrm{T}}$ is attributed to constructive and destructive interference between the swimbladder and the fish body. A direct relationship between dorsal swimbladder area and TS has not been observed and is not expected to exist for any fish species.

The use of radiographic imaging facilitated additional variables being added to acoustic size to $L_{\mathrm{T}}$ regression equations. GAMM regression was an appropriate approach as multiple measurements were taken from a group of individuals, with the resulting error term representing a mixture of group and population effects (Wood, 2006b). The use of splines (i.e. smooths) when modelling covariates has the advantage that no assumptions are made about relationships among covariates or the response variable. A disadvantage is that this technique is relatively new and that standardized procedures to measure significance are somewhat ad hoc and exploratory (Wood, 2006a). Final GAMMs showed that multi-covariate models were better predictors of TS than $L_{\mathrm{T}}$ alone (i.e. $r^{2}$ values increased and AIC values were lower at 38 and 120 $\mathrm{kHz}$ ). If these additional variables were added to TS and $L_{\mathrm{T}}$ regression equations, then fish body elongation ratio data could be obtained from field measurements but swimbladder angles could not be determined without advanced imaging techniques. The fact that swimbladders can deviate up to $10^{\circ}$ posterior 
down from horizontal (Blaxter \& Batty, 1990; Clay \& Horne, 1994) depending on $L_{\mathrm{T}}$ (Fig. 9) and species, makes inclusion of swimbladder angles impractical for acoustic size to $L_{\mathrm{T}}$ regressions when based on in situ TS measurements. As an alternative, TS and length regression models have been developed using fish-aspect distributions and transducer beam shapes (Foote, 1980b; K. Olsen, unpubl. data). This practice is not standard when estimating population abundances using acoustic data, and the number of published tilt-angle distributions is limited. Additional fish tilt and swimbladder angle measurements are needed to quantify intraspecific and interspecific variability in swimbladder orientation and to validate generalization of fish orientation when converting acoustic sizes to fish sizes.

I thank P. Geisen, E. Hazen and J. Sweet for radiograph measurements and digitizing. Data management were greatly aided by R. Latham. Fish rearing was supervised by $\mathrm{M}$. Tetrick at the University of Washington Fish Hatchery. This manuscript was improved by reviews from S. Parker-Stetter, P. Walline, two anonymous reviewers and R. Wootton. This work was supported by the Office of Naval Research and the Alaska Fisheries Science Center.

\section{References}

Abe, K., Sadayasu, K., Sawada, K., Ishii, K. \& Takao, Y. (2004). Precise target strength measurement of juvenile walleye pollock (Theragra chalcogramma). Proceedings of Oceans '04 MTS/IEEE Techno-Ocean '04 1, 370-374.

Akaike, H. (1974). A new look at the statistical model identification. IEEE Transactions on Automatic Control 19, 716-723.

Alexander, R. M. (1966). Physical aspects of swimbladder function. Biological Reviews 41, 141-176.

Amorim, M. C. P. \& Hawkins, A. D. (2005). Ontogeny of acoustic and feeding behaviour in the grey gunnard, Eutrigla gurnardus. Ethology 111, 255-269.

Bailey, H. C. \& Doroshev, S. I. (1995). The duration of the interval associated with successful inflation of the swimbladder in larval striped bass (Morone saxatilis). Aquaculture 131, 135-143.

Barton, B. A. (1996). General biology of salmonids. In Principles of Salmonid Culture (Pennell, W. \& Barton, B. A., eds), pp. 29-95. Amsterdam: Elsevier.

Blaxter, J. H. S. \& Batty, R. S. (1990). Swimbladder "behavior" and target strength. Rapports et Process-verbaux des Réunions Conseil internationale pour l'Exploration de la Mer 189, 233-244.

Burczynski, J. J., Michaletz, P. H. \& Marrone, G. M. (1987). Hydroacoustic assessment of the abundance and distribution of rainbow smelt in Lake Oahe. North American Journal of Fisheries Management 7, 106-116.

Butler, J. L. \& Pearcy, W. G. (1972). Swimbladder morphology and specific gravity of myctophids off Oregon. Journal of the Fisheries Research Board of Canada 29, 1145 1150 .

Carlander, K. D. (1969). Handbook of Freshwater Fishery Biology, Vol. 1. Ames, IA: Iowa State University Press.

Charrier, I., Mathevon, N. \& Jouventin, P. (2001). Mother's voice recognition by seal pups. Nature 412, 873.

Clay, C. S. \& Horne, J. K. (1994). Acoustic models of fish: the Atlantic cod (Gadus morhua). Journal of the Acoustical Society of America 96, 1661-1668.

Cordue, P. L., Coombs, R. F. \& Macaulay, G. J. (2001). A least squares method of estimating length to target strength relationships from in situ target strength distributions and length frequencies. Journal of the Acoustical Society of America 109, 155-163. 
Donaldson, L. R. (1968). Selective breeding of salmonid fishes. In Marine Aquaculture (McNeil, W. J., ed.), pp. 65-74. Corvallis, OR: Oregon State University Press.

Doroshev, S. I., Cornacchia, J. W. \& Hogan, K. (1981). Initial swimbladder inflation in the larvae of physoclistous fishes and its importance for larval culture. Rapports et Procès-verbaux des Réunions Conseil internationale pour l'Exploration de la Mer 178, 495-500.

Edwards, J. I. \& Armstrong, F. (1984). Target strength experiments on caged fish. Scottish Fisheries Bulletin 48, 12-20.

Fahrmeir, L. \& Lang, S. (2001). Bayesian inference for generalized additive mixed models based on Markov random field priors. Applied Statistics 50, 201-220.

Foote, K. G. (1980a). The importance of the swimbladder in acoustic scattering by fish. Journal of the Acoustical Society of America 67, 2084-2089.

Foote, K. G. (1980b). Averaging of fish target-strength functions. Journal of the Acoustical Society of America 67, 504-515.

Foote, K. G. (1985). Rather-high-frequency sound scattering by swimbladdered fish. Journal of the Acoustical Society of America 78, 688-700.

Foote, K. G. \& Traynor, J. J. (1988). Comparison of walleye pollock target strength estimates determined from in situ measurements and calculations based on swimbladder form. Journal of the Acoustical Society of America 83, 9-17.

Gauthier, S. \& Horne, J. K. (2004). Acoustic characteristics of forage fish species in the Gulf of Alaska and Bering Sea based on Kirchhoff-approximation models. Canadian Journal of Fisheries and Aquatic Sciences 61, 1839-1850.

Harden Jones, F. R. \& Scholes, P. (1985). Gas secretion and resorption in the swimbladder of the cod Gadus morhua. Journal of Comparative Physiology B 155, 319-331.

Haslett, R. W. G. (1962). The back-scattering of acoustic waves in water by an obstacle II: determination of the reflectivities of solids using small specimens. Proceedings of the Physical Society 79, 559-571.

Horne, J. K. (2003). The influence of ontogeny, physiology, and behaviour on the target strength of walleye pollock (Theragra chalcogramma). ICES Journal of Marine Science 60, 1063-1074.

Horne, J. K. \& Jech, J. M. (1999). Multi-frequency estimates of fish abundance: constraints of rather-high frequencies. ICES Journal of Marine Science 56, 184-199.

Horne, J. K. \& Jech, J. M. (2005). Models, measures, and visualizations of fish backscatter. In Sounds of the Seas: From Ocean Acoustics to Acoustical Oceanography (Medwin, H., ed.), pp. 374-397. New York: Cambridge University Press.

Horne, J. K., Walline, P. D. \& Jech, J. M. (2000). Comparing acoustic model predictions to in situ backscatter measurements of fish with dual-chambered swimbladders. Journal of Fish Biology 57, 1105-1121.

Huxley, J. (1932). Problems of Relative Growth. London: Methuen.

Jech, J. M., Schael, D. M. \& Clay, C. S. (1995). Application of three sound scattering models to threadfin shad (Dorosoma petenense). Journal of the Acoustical Society of America 98, 2262-2269.

Jørgensen, R. (2003). The effects of swimbladder size, condition and gonads on the acoustic target strength of mature capelin. ICES Journal of Marine Science 60, $1056-1062$.

Lin, X. \& Zhang, D. (1999). Inference in generalized additive mixed models using smoothing splines. Journal of the Royal Statistical Society 53, 211-225.

Lower, N., Moore, A., Scott, A. P., Ellis, T., James, J. D. \& Russel, I. C. (2005). A noninvasive method to assess the impact of electronic tag insertion on stress levels in fish. Journal of Fish Biology 67, 1202-1212. doi: 10.1111/j.1095-8649.2005.00815.x

McCartney, B. S. \& Stubbs, A. R. (1971). Measurements of the acoustic target strengths of fish in dorsal aspect, including swimbladder resonance. Journal of Sound and Vibration 15, 397-420.

McClatchie, S., Alsop, J. \& Coombs, R. F. (1996). A re-evaluation of relationships between fish size, acoustic frequency, and target strength. ICES Journal of Marine Science 53, 780-791. 
McClatchie, S., Macaulay, G. J. \& Coombs, R. F. (2003). A requiem for the use of $20 \log 10$ Length for acoustic target strength with special reference to deep-sea fishes. ICES Journal of Marine Science 60, 419-428.

McCowan, B. \& Reiss, D. (1995). Whistle contour development in captive-born infant bottlenose dolphins (Tursiops truncatus): role of learning. Journal of Comparative Psychology 109, 242-260.

McEwen, R. S. (1940). The early development of the swim bladder and certain adjacent parts in Hemichromis bimaculata. Journal of Morphology 67, 1-59.

Nakken, O. \& Olsen, K. (1977). Target-strength measurements of fish. Rapports et Procèsverbeaux des Réunions Conseil international pour l'Exploration de la Mer 158, 18-23.

Sand, O. \& Hawkins, A. D. (1973). Acoustic properties of the cod swimbladder. Journal of Experimental Biology 58, 797-820.

Schwarz, A. (1971). Swimbladder development and function in the haddock, Melanogrammus aeglefinus L. Biological Bulletin 141, 176-188.

Summerfelt, R. C. \& Smith, L. S. (1990). Anesthesia, surgery, and related techniques. In Methods for Fish Biology (Schreck C. B. \& Moyle, P. B., eds), pp. 213-272. Bethesda, MD: American Fisheries Society.

Whitehead, P. J. P. \& Blaxter, J. H. S. (1964). Swimbladder form in clupeoid fishes. Zoological Journal of the Linnean Society 97, 299-372.

Williamson, N. J. \& Traynor, J. J. (1984). In situ target-strength estimation of Pacific whiting (Merluccius productus) using a dual-beam transducer. Journal du Conseil international pour l'Exploration de la Mer 41, 285-292.

Wood, S. N. (2006a). Generalized Additive Models: An Introduction with R. New York: Chapman \& Hall.

Wood, S. N. (2006b). Low-rank scale-invariant tensor product smooths for generalized additive mixed models. Biometrics 62, 1025-1036.

Wysocki, L. E. \& Ladich, F. (2001). The ontogenetic development of auditory sensitivity, vocalization and acoustic communication in the labyrinth fish Trichopsis vittata. Journal of Comparative Physiology A 187, 177-187.

\section{Electronic References}

Abe, K., Sadayasu, K., Sawada, K., Ishii, K. \& Takao, Y. (2005). Precise target strength measurement of juvenile walleye pollock (Theragra chalcogramma) with consideration for morphology of swimbladder. In Proceedings of the International Conference, Underwater Acoustics Measurements: Technologies \& Results (Papadakis, J. S. \& Bjørnø, L., eds). Available at http://promitheas.iacm.forth.gr/uameasurements 2005/Proceedings/Main\%20menu.pdf

R Development Core Team (2007). R: A Language and Environment for Statistical Computing. Vienna: R Foundation for Statistical Computing. Available from http://www.r-project.org 